\title{
Pavement Design in the USA
}

\author{
Andrey Korochkin ${ }^{1 *}$ \\ ${ }^{1}$ MADI, Leningradsky Prospekt, 64, Moscow, 125319, Russian Federation
}

\begin{abstract}
The methodology for calculating pavements used in the United States is discussed in this article. The article contains the principles of pavement design outlined in the manual "P. Design of New and Reconstructed Flexible Pavements. Part 3", which are used by designers not only in the United States, but also in many countries around the world. Differences in approaches to pavement design in the Russian Federation and the United States are shown. It is marked that in difference from Russia, where requirements documents are valid on all territory of the country, in America each state develops its own requirements documentation, however the general principles of designing presented in the above-mentioned manual, remain invariable. In order to compare the pavement structures used in Russia and the USA the author has given examples of constructions developed on the basis of the US guidelines and has shown the main differences of these constructions from those which are traditionally applied in our road construction. In addition, the author draws attention to the fact that in contrast to Russia in the U.S. roads usually have a non-rigid type of pavement, which significantly increases their strength and durability.
\end{abstract}

\section{Introduction}

In the design of highways, pavement structures are always given special attention. First of all, because of the high estimated cost of road pavements, which is sometimes up to $60 \%$ of the cost of all construction and installation work. Therefore, usually the roadway design is selected on the basis of technical and economic comparison of several suitable options, choosing the cheapest of them. Secondly, road's transport-operational qualities, including traffic safety and convenience of movement on it, are mainly estimated by the state of road clothes. Therefore, it is not surprising that design of road pavements in our country, as well as abroad, are the subject of many scientific papers, which give the basic principles of design and methods of calculations of pavements were developed to optimize designs and fix them to specific conditions.

In our country, the principle of road pavement design is based on the calculation method, based on the theory of elasticity, which allows to estimate the strength of road pavement depending on the number of applications of various loads [1]. This procedure, named the "Soyuzdorniya method", was developed in 1943 by professor N. N. Ivanov [2], who proposed this form of calculation and later worked much on its improvement.

\footnotetext{
* Corresponding author: andrey_korochkin@mail.ru
} 
Along with him, this topic was actively pursued by professors A.K. Birulia [3], V.F. Babkov [4] and many other Soviet and Russian scientists who have made a great contribution to the development of road pavement calculation methods. Their scientific research was the basis for the appearance of methodical and regulatory documents governing the calculation of road pavements, which over time have been updated and supplemented by new data.

Currently in Russia the calculation of road pavements is performed according to three requirements documents:

- "Methodical recommendations for the design of rigid road pavements" in 2004;

- ODN 218.046-01;

- PNST 265-2018.

The calculation methods in these documents, as well as in previous requirements documents, are based on the definition of the pavement design as a single complex.

In addition to these documents, which contain calculation procedures, some other standards, such as SP 34.13330.2012, GOST R 52748-2007, GOST 32690-2014, provide a set of basic design parameters, which are used to calculate the road pavements.

In general, the principle of calculation of road pavement is good, because it allows to define the required design of pavement in each specific case, taking into account the geographical location, geological and natural conditions, perspective traffic intensity, taking into account construction materials, etc. But at the same time, it requires the consideration of a large number of design parameters, which become outdated with time due to changing traffic conditions on the roads and require constant updating. That does not always happen in time, and that is why there are certain errors in calculations [5].

Nevertheless, this calculation technique gives good results and is widely used not only in Russia, but also abroad, primarily in the CIS countries.

But at the same time around the world there are other methods by which the design and construction of road pavements of highways are carried out. These methods are based on the work of famous Western scientists such as Westergaard H. M. [6], Franklin R.E. [7], Burmister D. M. [8, 9], Pickett G. [10], Groney D. [11]. In this article we offer to your attention the principles of design and calculation of road pavements in the USA, which, as it is known, are the world leaders in the field of construction of highways.

\section{Pavement Design in the United States}

The methods of calculation and design of pavements in the United States are outlined in the manual P. Design of New and Reconstructed Flexible Pavements. Part 3 [12] (hereinafter Manual). According to this guideline, pavements are calculated from the conditions of resistance to damage taking into account the prediction of various types of such damage. The following groups of failures are defined:

- fatigue;

- destructions due to loads during operation;

- destructions connected with the influence of natural and climatic conditions.

According to the Guidelines methodology the design of road pavements is carried out in several stages. First there is the preliminary design of road pavement, which depends on the parameters of the road, its purpose and the climatic and geological conditions of the places where the projected road will be situated. At the same time materials for the construction of road pavement layers are selected, as well as their quantity and thickness.

Then calculated parameters of destructions, which will influence on the designed roadway are determined. After that the resistance of the pavement to damage is simulated and the performance of the pavement is predicted. 
In the final step, after adjustments made with the modeling and prediction data, the final version of the pavement is adopted.

\section{Pavement modeling and performance prediction}

In the United States, pavement modeling is the basis of design. The task of modeling includes determining the resistance of the pavement structure to both loads and adverse environmental effects. A large number of input parameters are taken into account, such as: pavement layer thicknesses, material properties, elastic properties, moisture, vehicle characteristics and traffic conditions, load distribution, tire contact area with the roadway, pavement service life, vehicle speed, etc.

With the help of modeling, critical points of the pavement, where the destructive effects will have the maximum value, are determined. It is for these points that the performance characteristics of the entire structure are determined.

The critical points are determined depending on the type of failure. In the case of fatigue failure, the pavement surface is considered first. Then the pavement to a depth of 0.5 inch $(1.25 \mathrm{~cm})$. And then the bottoms of all bound or reinforced layers. As for rutting, attention is paid to the midpoints of all structural layers as well as to the subgrade: its top and to a depth of 6 inches $(15 \mathrm{~cm})$ from the surface of the subgrade.

Next step after modeling probable pavement failures and determining critical points, is to predict its performance characteristics. These characteristics depend on the ability of the pavement to resist failure. The accumulation of damage in this case is considered as a function of vehicular traffic and time.

From Manual's point of view, the main pavement failures are rutting and cracking (fatigue and temperature). Predicting these failures one is of the most important parts of pavement design.

So, to solve the rutting problem, a system of analysis is used to determine the degree of residual deformation of asphalt concrete and other bitumen-treated layers and layers made of unbound materials. To predict rutting, various factors influencing their formation and magnitude are considered: thickness of asphalt concrete layers, amount and grade of binder, porosity, base thickness, type of traffic loads, traffic intensity, temperature of pavement layers, etc.

In its turn, fatigue cracking is associated primarily with traffic loads, due to which residual deformations and stresses arise, leading to destruction. And if fracture occurs at a critical point, cracks begin to propagate throughout the bound layer.

When predicting temperature cracking, the main emphasis is placed on the viscoelastic transformation theory, based on which the relationship between the plastic deformations of asphalt concrete and its relaxation modulus is derived. That makes it possible to predict the temperature stresses in asphalt concrete layers at any depth. The results of such prediction allow to effectively choose the asphalt concrete mixture of optimal stiffness to resist the temperature destruction.

It is necessary to tell separately about forecasting of pavement evenness.

If the types of damage associated with transport loads and natural-climatic conditions (rutting, cracking) are predicted using mechano-empirical methods, the damage in the form of a grid of cracks, potholes, small surface deformations, can not be determined by these methods. But, nevertheless, they have a serious impact on the uniformity of the coating. It should be taken into account that in the United States it is pavement evenness that is the main criterion of road quality evaluation. Therefore, to predict pavement evenness IRI has developed a special methodology, which consists of the following steps:

- predicting pavements failures; 
- choice of initial IRI values, determination of probable failures (longitudinal cracking, potholes areas, joint pitting)

- selection of suitable IRI models to predict for the anticipated service life of the road.

After the performance of road pavements is predicted and possible damages are determined, the preliminary pavement design is adjusted to the obtained data. After that the calculation is considered completed.

\section{Pavement Designs for U.S. Highways}

In addition to calculation, modeling, and forecasting techniques, the Manual includes a large number of typical design solutions. Analysis of these will allow us to understand how roadways in the United States differ from the roadways used in our country. As an example, let's look at the designs used in highway construction.

Let's start with non-rigid type roadways.

The manual offers a lot of standard designs with asphalt-concrete pavement. Asphalt may be paved on the basis of different materials, both non-cohesive or reinforced with mineral or organic binders. There are many constructions where the same asphalt concrete is proposed as the base. For our analysis we will choose a construction more traditional for us.

In our case the pavement is made of two layers of asphalt concrete mixture. The top layer is 1 inch $(2.5 \mathrm{~cm})$ thick. In the USA, the top layer of asphalt concrete pavement not only has a small thickness, but also is divided into two sub-layers of half-inch $(1.25 \mathrm{~cm})$. They believe that asphalt aging occurs in the top sub-layer, while the lower layers are not severely affected. On the other hand, the bottom layer is asphalt concrete pavement with a thickness of up to $20 \mathrm{~cm}$.

The pavement is followed by a two-layer binder-treated base that is made from unbound materials. The thickness of the top layer of the base is $15 \mathrm{~cm}$ and the bottom layer is $20 \mathrm{~cm}$.

Then - an additional layer of the base, two-layered as well. The thickness of each layer should be no less than $30 \mathrm{~cm}$.

Let's try to bring the obtained design in accordance with our regulatory documents. As a result we have the following:

- the top layer of the pavement made of SCHMA [stone mastic asphalt]-15 (GOST 31015 ) with a thickness of $3 \mathrm{~cm}$;

- the bottom layer of fine-grained dense asphalt concrete, type A, grade I (GOST 91282013) $20 \mathrm{~cm}$ thick

- top layer of the black crushed stone base (GOST 30491-2012) $15 \mathrm{~cm}$ thick

- the bottom layer of the basement made of crushed stone M800 (GOST 8267-93), laid by the wedging method, $20 \mathrm{~cm}$ thick;

- the upper base layer of crushed stone-sand mixture C9 (GOST 25607-2009) $30 \mathrm{~cm}$ thick;

- the bottom spreading layer of medium sand (GOST 8736-2014) $30 \mathrm{~cm}$ thick;

The resulting structure is shown in Fig. 1. 


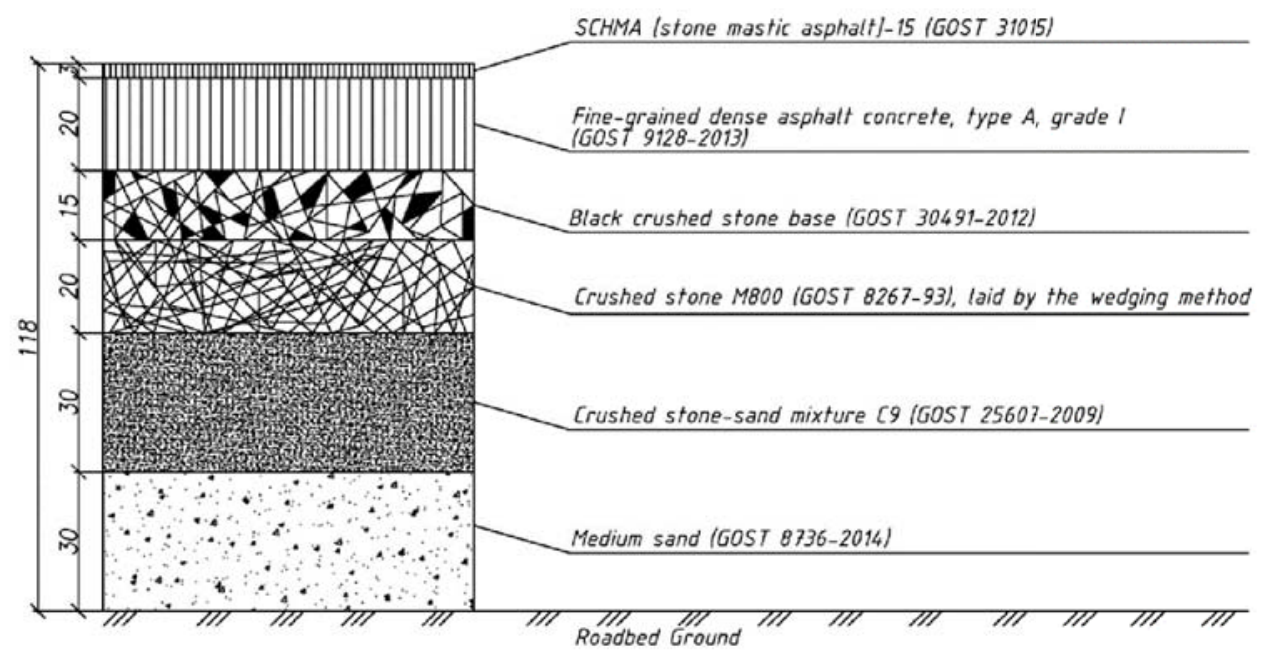

Fig. 1. Nonrigid type road pavement adapted to the Russian standards (dimensions are given in centimeters)

It is hard to say whether this design is applicable to Russian conditions without special investigations. But the principal difference from the road pavement familiar to us can be seen with the naked eye. First of all it is a multilayer structure. By the way, the "sandwich" type of road pavement, recommended by the same Manual, is widely used in the USA. In this type of construction the monolithic dense layers are alternated with unbound layers, which, according to the American road builders, increases the durability of the roadway. Keep in mind, however, that the Manual presented here provides general principles for pavement design, while most of the design parameters used in modeling and forecasting vary, depending on the regulatory framework of the state in which the road construction takes place. And what is appropriate for one state may well not apply in another.

Now let's consider rigid-type roadways.

As we know, in the United States, hard-type pavements with cement-concrete pavement are widely used in highway construction. So let's take a closer look at them. In his work devoted to the construction of roads with cement concrete pavement in the U.S., B.S. Radovsky [13] gives examples of rigid pavements.

Here, layering is out of the question. There are only 3 classic layers: the coating, the base, the substrate. The covering is made of cement concrete. The base is made of "lean concrete", asphalt concrete or crushed stone. Bedding layers are made of unbound materials. Let's consider 3 types of road pavements. Also, we will try to adapt them to our domestic standards.

Options for the state of California.

1st option:

- $27 \mathrm{~cm}$ thick cement concrete pavement [cement concrete class 4,4 mark 55 GOST 26633-2015];

- $15 \mathrm{~cm}$ thick lean concrete base;

$-21 \mathrm{~cm}$ thick base course [stone sand mixture C9]. 


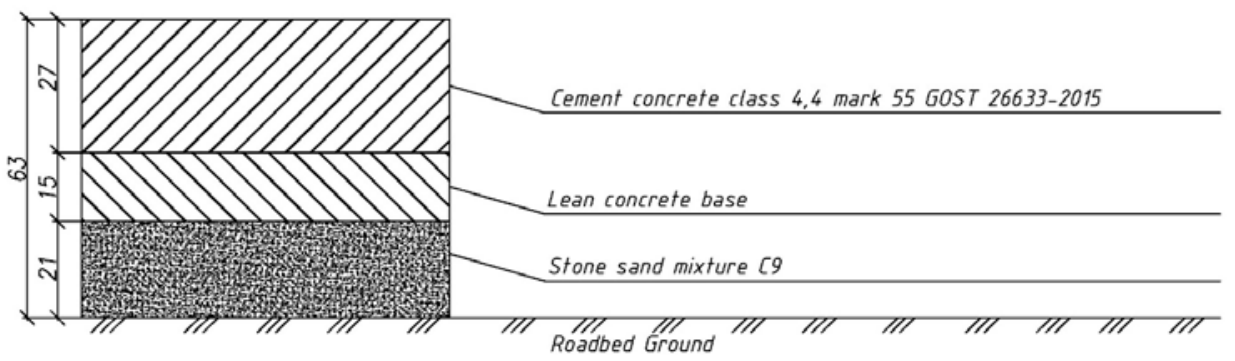

Fig. 2. Rigid-type road pavement in the state of California (option 1) adapted to the Russian standards (the dimensions are given in centimeters)

Option 2:

- pavement of cement concrete with a thickness of $22.5 \mathrm{~cm}$ [cement concrete class 4,4 mark 55 GOST 26633-2015];

- base of porous asphalt concrete with a thickness of $15 \mathrm{~cm}$ [porous asphalt concrete, coarse-grained, on construction bitumen 60/90, GOST 9128-2013]

- 21-cm thick base course [stone sand mixture C9].

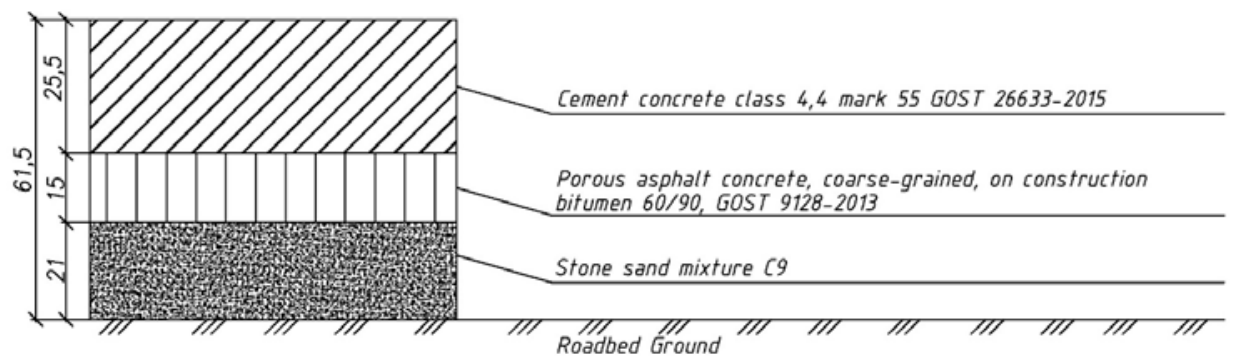

Fig. 3. Rigid type pavement in California (option 2) adapted to the Russian standards (the sizes are given in centimeters)

But in the state of Washington with more severe climate, than in California the pavement designs have their own peculiarities. Firstly, there more attention is paid to the underlying layer, the thickness of which is $30-50 \mathrm{~cm}$. This is because of the frequent rains that fall in autumn and winter period. Secondly, the thickness of the cement concrete pavement layer is somewhat greater there than in the southern states.

Let's consider a pavement with a cement concrete pavement on a base of crushed stone:

- $33.5 \mathrm{~cm}$ thick cement concrete pavement [cement concrete class 4,4 mark 55 GOST 26633-2015];

- base of crushed stone $15 \mathrm{~cm}$ thick [crushed stone M800 (GOST 8267-93), laid by the wedging method];

- base course with a thickness of $50 \mathrm{~cm}$ [crushed stone-sand mixture C9 (GOST 256072009)]. 


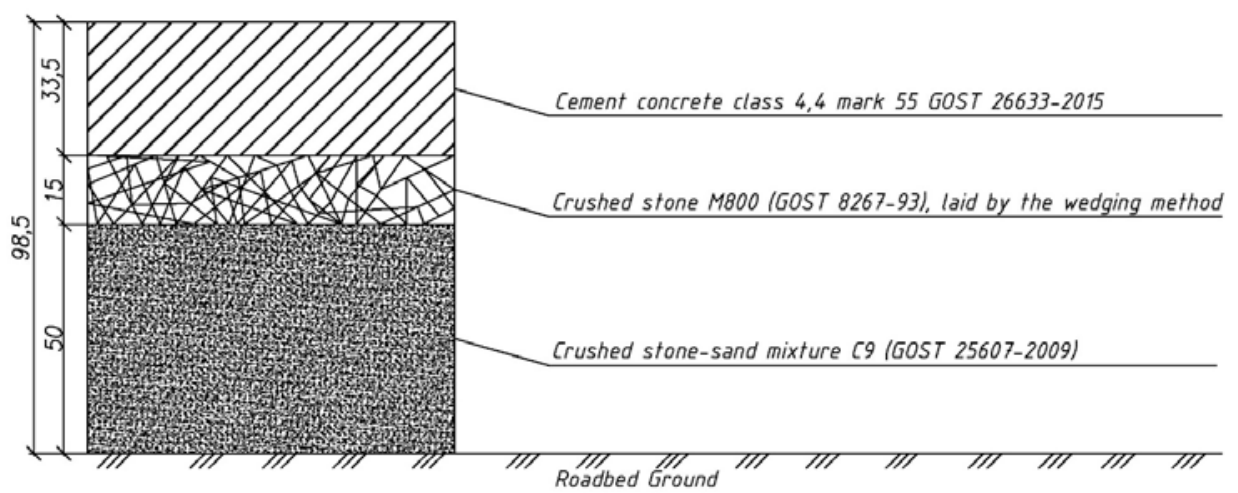

Fig. 4. Rigid type road pavement in the State of Washington adapted to the Russian standards (dimensions are given in centimeters)

As can be seen from the above examples of rigid pavement structures used in the U.S., the thickness of cement concrete pavement in them is much greater than that used in Russian domestic road construction, while the base is arranged in a small thickness and can not be a load-bearing layer. That is, the main load-bearing element of the road structure is a monolithic cement concrete slab. All other structural layers are of auxiliary importance.

Such a thickness of the cement concrete pavement, without any doubt, significantly increases the strength of the pavement and its durability. And, considering the fact that the main highways in the United States have a rigid road surface, it becomes clear what the famous quality of American roads is based on.

Unfortunately, in Russia the attitude to roads with rigid pavement, and especially to those with cement concrete pavement, is rather cold. Asphalt concrete is firmly entrenched in our life, and the bulk of the roads under construction have non-rigid type pavement. Although studies of many modern scientists prove that rigid pavements are much more effective in modern conditions with a rapid increase in the intensity and speed of traffic on the roads, increasing the capacity of vehicles, especially on highways and roads of high categories [14], [15], [16].

\section{Conclusion}

The analysis of pavement calculation methods used in the USA shows:

1. American methods of calculation of pavements are fundamentally different from the methods used in Russian domestic practice.

2. The main emphasis in calculations of pavements according to Manual is made on modeling of probable destructions and prediction of resistance of pavement to these destructions.

3. The design of nonrigid pavements in the United States makes extensive use of multilayered structures, including the use of sandwich-type road structures.

4. Rigid pavement structures differ from those used in the Russian Federation with greater thickness of cement concrete pavement, which is the main load-bearing element.

5. Most highways in the U.S. are built with rigid type pavement, which positively affects the quality of the entire road network, increasing the strength of pavements and their durability. The same success can be achieved in Russia if rigid type pavements are built at least on roads of categories I and II. 


\section{References}

1. A.V. Korochkin, Specifics of calculating required strength of highway pavements, Transportation Research Procedia., Vol. 50. pp. 290-301. (2020)

2. N.N. Ivanov Design and calculation of non-rigid road pavement, N.N. Ivanov. Moscow: Transport, 328 c. (1973)

3. A.K. Birulia Design of Highways. Part 1, a textbook for universities, A.K. Birulia. 4-th edition. M. , Avtotransizdat, 498 c. (1961)

4. V.F. Babkov Designing highways. T. 1, V.F. Babkov, O.V. Andreev. - Moscow: Transport, 368 c. (1987)

5. A.V. Korochkin, The required strength of road pavement structures of highways. Monograph. M. Tekhpoligraftsentr, (2020).

6. H. Westergaard New formulas for stresses in concrete pavements of airfields , Transactions ASCE, Vol. 113, P. 434. 47,(1948)

7. R.E. Franklin, Frost scaling on concrete roads. RRL Report LR 117, Crowthorne: Road Research Laboratory, p.24. (1967)

8. D.M. Burmister The theory of stresses and displacements in layered systems and application to the design of airport runways, Proc. highway research board. Washington 23, pp. 126-144 (1943)

9. D.M. Burmister The general theory of stresses and displacement in layered soil systems, / Journal appl. physics. 16 (5). pp. 296-302. (1945)

10. G. Pickett Concrete pavement design: Appendix III. A study of stresses in the comer region of concrete pavement slabs under large comer loads, Portland cement association. - Chicago, pp. 77-87. (1951)

11. Groney D. The desiqn and performance of road pavements, London: Her majesty's stationery office, 673 p. (1977)

12. P. Missouri, Design of New and Reconstructed Flexible Pave-ments. Part 3. Chapter 3: Guide for Mechanistic-Empirical Design of New and Rehabilitated Pavement Structures, P. Missouri., Washington : Aashto, p.115 (2004)

13. B.S. Radovsky, Cement concrete pavements in the United States: structures, Automobile Roads, 2, p.48. (2015)

14. L.B. Kamenetsky. Efficiency of cement concrete. Automobile roads, No. 3(988), (2014)

15. A.V. Korochkin, Investigation of rigid road pavement with asphalt concrete pavement in urban conditions. Transport Construction, 7 pp.8-11. (2012)

16. A.V. Korochkin, Influence of type and thickness of cement- concrete on the calculation of rigid road surfaces with asphalt-concrete pavement, IOP Conference Series: Materials Science and Engineering. International Multi-Conference on Industrial Engineering and Modern Technologies («FarEastCon»), Vladivostok, Russky Island, 1-4 October (2019) 